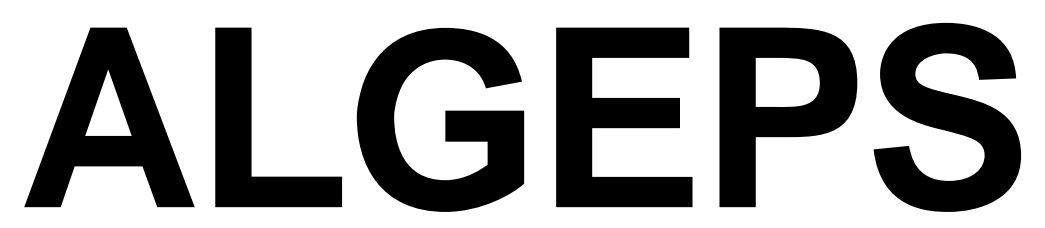

REVISTA DE GEOLOGIA, SÈRIE B no 603 - Setembre del 2012

\begin{abstract}
RECORREGUT DE RECERCA GEOLÒGICA, GEOAMBIENTAL I MINERALÒGICA PER LES COMARQUES DE L'ALT PENEDÈS I D’ANOIA: DES D'AVINYONET DEL PENEDÈS A SUBIRATS, SANT SADURNÍ D’ANOIA, PIERA I A VALLBONA D'ANOIA
\end{abstract}

Josep M. Mata-Perelló

Aquest recorregut va ésser experimentat amb docents el dia 19 DE GENER DEL 2011 


\title{
RECORREGUT DE RECERCA GEOLÒGICA, GEOAMBIENTAL I MINERALÒGICA PER LES COMARQUES DE L'ALT PENEDÈS I D'ANOIA: DES D'AVINYONET DEL PENEDÈS A SUBIRATS, SANT SADURNÍ D’ANOIA, PIERA I A VALLBONA D'ANOIA / 19b DE GENER DEL 2011
}

\author{
Per Josep M. MATA-PERELLÓ
}

\section{ADVERTIMENTS PREVIS}

Com en altres recorreguts de RECERCA GEOLÒGICA I MINERALÒGICA ..., aquest constarà de diverses parades. Però, sols si es disposa del temps suficient, podrà efectuar-se passant per totes les parades $i$ filloles. En cas contrari, recomanem prescindir de les anomenades PARADES - CONDICIONALS.

Pel que fa als camins per on transitarà el recorregut de l'itinerari, cal dir que en general es trobaran en bones condicions. Tot i així, sempre que sigui possible, recomanem demanar la màxima informació, en relació al estat real dels camins. En cas de trobar-se en males condicions, recomanem fer el desplaçament a peu.

En qualsevol cas, cal tenir sempre una cura molt especial de respecte a la natura, al llarg de tot el recorregut; de l'itinerari.

\section{BREU INTRODUCCIÓ}

El recorregut del present itinerari discorrerà, en la seva totalitat per una sola unitat geològica: pel Sistema Mediterrani (i més concretament, ho farà per dues de les quatre sotsunitats que el constitueixen: per la Depressió Prelitoral Catalana per la Serralada Prelitoral Catalana. Tot i així, en els trams inicials discorrerà molt proper a la Serralada Litoral Catalana.

Així, l'itinerari s'iniciarà a la localitat d'Avinyonet del Penedès, gairebé a la Serralada Litoral Catalana. Pels voltants d'aquest poble es faran les primeres aturades. Després, en anar cap a Sant Sadurní d’Anoia i Piera, el recorregut es farà per la Depressió Prelitoral Catalana. Posteriorment, en sobrepassar la població de Piera, s'entrarà a la Serralada Prelitoral Catalana, per on finalitzarà el recorregut d'aquest itinerari, per les immediacions de Vallbona d'Anoia, prop de Capellades.

Per d'altra banda, el recorregut de l'itinerari, haurà anat oscil-lant entre la comarca de l’Alt Penedès i la d’Anoia. En efecte, s'iniciarà a la primera a Avinyonet del Penedès, discorrent 
per aquesta comarca entre aquest poble i les immediacions de Piera. Posteriorment, en arribar a aquest darrer municipi ja es circularà per la comarca d'Anoia, per on finalitzarà el recorregut de l'itinerari, ja dintre de la Catalunya Central.

\section{OBJECTIUS FONAMENTALS}

Els objectius fonamentals que es pretenen aconseguir en el recorregut d'aquest itinerari, es poden concretar en els següents aspectes generals:

1.- Observació del Sistema Mediterrani, així com de les diferents sotsunitats que la constitueixen, i per les quals discorre el recorregut del present itinerari, entre les poblacions d'Avinyonet del Penedès (a l’Alt Penedès) i Vallbona d'Anoia (Anoía).

2.- Observació de la Serralada Litoral Catalana, prop de la qual discorrerà l'itinerari entre Avinyonet del Penedès i Santa Pau de 1’Ordal. I dintre d'aquesta sotsunitat: observació i descripció dels materials mesozoics (del Triàsic i del Cretàcic exclusivament), els quals constitueixen la Serralada Litoral Catalana, pels voltants de les poblacions esmentades d'Avinyonet del Penedès i santa Pau de 1’Ordal.

3.- Observació de la Depressió Prelitoral Catalana, per la qual discorrerà bona part de l'itinerari entre Avinyonet del Penedès (Alt Penedès) i Piera (Anoia). I alhora, reconeixement dels materials cenozoics (del terciari i del quaternari) que la constitueixen.

4.- Observació de la Serralada Prelitoral Catalana, prop de la qual discorrerà l'itinerari entre Piera, Vallbona d'Anoia i Capellades. I dintre d'aquesta sotsunitat: observació i descripció dels materials paleozoics (fonamentalment de l’Ordovicià). Així com dels mesozoics (del Triàsic), els quals constitueixen aquesta serralada.

5. - Observació de les estructures locals d'aquests materials esmentats al paràgraf anterior, al llarg del recorregut de l'itinerari. I alhora, si s'escau, dels contactes entre la Serralada Litoral Catalana i la Depressió Prelitoral Catalana; i entre aquesta i la Serralada Prelitoral Catalana.

6.- Observació a distància, dels materials terciaris (del Paleocè a l’Eocè) que formen part de Montserrat, dintre de la llunyana Depressió Geològica de l'Ebre.

7.- Observació i reconeixement de diverses mineralitzacions situades a diferents indrets del recorregut de l'itinerari, fonamentalment de les mineralitzacions filonianes de piro.filita, encaixades entre els materials paleozoics de la Serralada Prelitoral Catalana. Nosaltres els veurem a la Mina de la Torre de la Fam (de Piera, a la comarca d'Anoia).

8.- Observació, si s'escau, i comentari de diverses explotacions mineres, antigues i actuals, situades al recorregut de l'itinerari, com les explotacions de pissarres de Piera (Anoía) ubicades a la Serralada Prelitoral Catalana.

9.- Interpretació dels impactes mediambientals provocats per les explotacions mineres sobre el Medi Natural i sobre el Medi Ambient. I en tot cas de les restauracions dutes a terme per tal de corregir els impactes. 
10.- Observació del Patrimoni Miner relacionat amb les explotacions mineres, que anirem veient al llarg del recorregut.

11.- Observació del Patrimoni Geològic que anirem trobant al llarg del recorregut de l'itinerari.

\section{ANTECEDENTS BIBLIOGRÀFICS}

Pel que fa al recorregut del present itinerari, existeixen alguns antecedents parcials, de tipus bibliogràfic referent a diferents parts del recorregut del mateix; es tracta de MATAPERELLÓ (1996a, 1996b, 1997, 1998, 1999, 2006A, 2006B i 2008). I també a MATA LLEONART et altri (2000). Trets d'aquests antecedents, no en tenim coneixement de cap altres.

Tot i així, farem esment d'un important treball de SOLE SABARÍS (1964), on es descriu un recorregut molt proper al que ara presentem, dintre d'un conjunt de recorreguts pels voltants de Barcelona.

Pel que fa a la descripció de les mineralitzacions de les comarques per les quals discorre 1'itinerari, cal parlar d'uns altres treballs nostres, de MATA-PERELLÓ (1988 i 1991), el primer relatiu al conjunt de les mineralitzacions catalanes en general, distribuïdes per comarques, $\mathrm{i}$ esmentant-se les corresponents al Baix Llobregat i al Vallès Occidental. També pot fer-se esment del treball comarcal de MATA-PERELLÓ (1988), en un treball relatiu a la comarca del Vallès Occidental i a la del Baix Llobregat.

I, finalment, pel que fa a l'estructura geològica de la zona per la qual discorre l'itinerari, farem esment dels treballs de: GUIMERÀ et altri (1982) i de RIBA et altri (1976). Tanmateix, farem esment de les fulles de ITGME (1976a i 1976b) relativa a la zona per on discorre el recorregut del present itinerari.

Tots aquests treballs referenciats, $\mathrm{i}$ d'altres, figuren esmentats per ordre alfabètic a l'apartat dedicat a la BIBLIOGRAFIA.

\section{RECORREGUT DE L'ITINERARI}

L'inici del recorregut de l'itinerari, es realitzarà ben a la població d'Avinyonet del Penedès, dintre de la Depressió Prelitoral Catalana, per`p tocant a la Serralada Litoral Catalana. Entorn a aquesta darrera població i a la de Sant Pau de l’Ordal, farem les primeres aturades de l'itinerari.

Després, el recorregut, es dirigirà cap a Sant Sadurní d'Anoia i posteriorment cap a Piera. Entorn d'aquesta darrera població es realitzaran diverses aturades. Tot seguit, el recorregut es dirigirà cap a Vallbona d'Anoia i Capellades per on es faran les darreres aturades. En aquests darrers recorreguts s'haurà anat inicialment per la Depressió Prelitoral Catalana i finalment, en sobrepassar Piera, s'haurà entrat a la Serralada Prelitoral Catalana, per on finalitzarà. 


\section{DESCRIPCIÓ DE L'ITINERARI}

Com ja es habitual, s'estructurarà en una sèrie d'estacions (parades o aturades), en les qual es faran descripcions geològiques o mineralògiques, si s'escau. En cada cas s'indicarà el número del mapa topogràfic a escala 1:50.000 on es troba l'indret.

En aquest cas, el recorregut de l'itinerari passarà exclusivament per dos dels fulls. Concretament ho farà per part del 391 (o d'Igualada), 392 (o de Sabadell), 419 (o de Vilafranca del Penedès) i 420 (dit de l'Hospitalet de Llobregat), de 1"Instituto Geográfico y Catastral", realitzat a l'escala de 1:50.000.

Així doncs, la relació i descripció de les aturades que composen aquest itinerari, és la següent:

PARADA 1. SORTIDA D’AVINYONET DEL PENEDÈS, (terme municipal d'Avinyonet del Penedès, comarca de 1'Alt Penedès). (Full 420).

El recorregut de l'itinerari el començarem a la població d’Avinyonet del Penedès. Enllà ens caldrà fer una aturada, just a la sortida del poble per la carretera $\mathrm{N}-340$ (tot anant cap a l'Ordal), a menys de $1 \mathrm{~km}$ del centre del poble.

En aquest recorregut, hem anat trobant afloraments dels materials cenozoics que pertanyen a Depressió Prelitoral Catalana, on ara estem situats. Així, per arreu es poden veure materials detrítics quaternaris, els quals cobreixen als terrenys terciaris del Miocè, que reblen l'esmentada Depressió Prelitoral Catalana.

Tot i així, pels voltants d'Avinyonet del Penedès, haurem vist els relleus de la Serralada Litoral Catalana, la qual es molt propera a la població.

PARADA 2. TRENCALL DE SANT SADURNÍ D’ANOIA, CARRETERA DE L'ORDAL, (Ordal, terme municipal de Subirats, comarca de l'Alt Penedès). (Full 420).

Després de realitzar l'aturada anterior, cal continuar per la carretera $\mathrm{N}-340$, anant sempre cap a l'Ordal. En arribar al trencall de la carretera de Sant Sadurní d’Anoia, farem una nova aturada, a uns 4`5 $\mathrm{Km}$ de la parada anterior.

En aquest recorregut, hem anat sempre circulant per la Depressió Prelitoral Catalana, on ara estem situats. Així, haurem trobat per arreu els materials detrítics quaternaris, els quals cobreixen als terrenys terciaris del Miocè, que reblen l'esmentada Depressió Prelitoral Catalana.

Tot i així, com a l'aturada anterior, prop d'on ara som, haurem trobat afloraments dels materials mesozoics, del Juràssic i del Cretàcic, de caràcter carbonatat. Aquests materials formen part de la propera Serralada Litoral Catalana. 


\section{PARADA 3. EXPLOTACIONS D’ARGILA DE LA VENTA, (veïnat del Bedorc, terme municipal de Piera, comarca d'Anoía). (Full 391).}

Després de fer l'aturada anterior, cal fer un recorregut per la carretera BV - 2428, amb la intenció d'arribar a la població de Sant Sadurní d’Anoia. Després, en arribar a aquesta població, cal continuar per les carreteres BV-2241 i BV - 2242. Així, anirem passant per la Fortesa i per Sant Jaume ses Oliveres. Posteriorment arribarem al Bedorc, continuant cap a Piera. Poc després de deixar el Bedorc (a uns $2-3 \mathrm{Km}$ de Piera), trobarem unes antigues explotacions d'argila, situades a l'esquerra de la carretera. Aquí farem una nova aturada, a uns $19 \mathrm{Km}$ de la darrrerament feta.

La totalitat d'aquest breu recorregut, s'ha efectuat per la Depressió Prelitoral Catalana, on continuem ara ens trobem situats, entre afloraments de nivells argilosos i detrítics miocènics, sovint recoberts per materials (també detrítics) del Quaternari. En aquest indret on hi ha la present aturada, es troben unes recents explotacions de materials lutítics terciàris, del Miocè Superior, i més concretament del Pontià, que es troben (a l'igual que Piera i el Bedorc) dintre de la Depressió Prelitoral Catalana.

En aquest cas, aquets nivells argilosos (que contenen freqüents intercal.lacions detrítiques amb nivells de palets enllargats de pissarres, procedeixen de l'erosió de les licorelles paleozòiques, probablement de l'Ordovicià) es troben en una petita conca de deposició, dintre del conjunt de la depressió anteriorment esmentada.

Entre els minerals presents, i que formen part dels nivells de lutites, cal fer esment dels següents: CAOLINITA, HAL.LOISITA i VERMICULITA. Aquests nivells van ésser explotats per al seu ús a unes properes ceràmiques; i també com a matèria prima d'una fàbrica d'àrids artificials i lleugers, per la seva qualitat d'argiles expansives.

PARADA 4. LES FLANDES, (veïnat del Bedorc, terme municipal de Piera, comarca d'Anoia). (Full 391).

Després de fer l'aturada anterior, cal entrar dintre de l'explotació, fins arribar a l'indret de les Flandes. Tot i que també es pot seguir cap a Piera, però a uns 1'5 Km abans d'arribar-hi es trobarà un camí que també va cap a les Flandes. En aquest indret es pot fer una nova aturada, entre 0’5 i 1'5 Km de l'anterior, segons el camí fet.

En aquest recorregut, hem anat circulant per la Depressió Prelitoral Catalana, entre els materials terciaris del Miocè, els quals es troben molt sovint recoberts per terrenys detrítics quaternaris, com hem vist abans.

Així en aquest lloc, ens trobem davant d'un aflorament dels materials miocènics constituïts per alternances de eludides de tonalitats ocres, per gresos, i per filades de còdols i palets procedents de l'erosió de les pissarres de la Serralada Prelitoral Catalana, que es troben més amunt i que veurem després

En aquest indret es troben unes interessants formacions de xaragalls (o "bad-lands"), desenvolupats sobre els nivells de eludides miocèniques. Aquests abarrancaments han conduït a 
la formació d'un conjunt molt bonic, el qual s'anomena amb el nom de les Flandes. Sense cap mena de dubte, tant per la seva espectacularitat i bellesa, com seu indubtable valor didàctic, es un indret molt important de la nostra geologia. És més creiem que es tracta d'un àrea a protegir (MATA-PERELLÓ i FONT, 1995).

Des del nostre punt de mira es un important PIG (Punt d'Interès Geològic), integrant del que podria ser el Parc Geològic de la Catalunya Central (MATA-PERELLÓ, 2004). Es, sense cap mena de dubte un punt interessant de la geologia de la comarca d'Anoia.

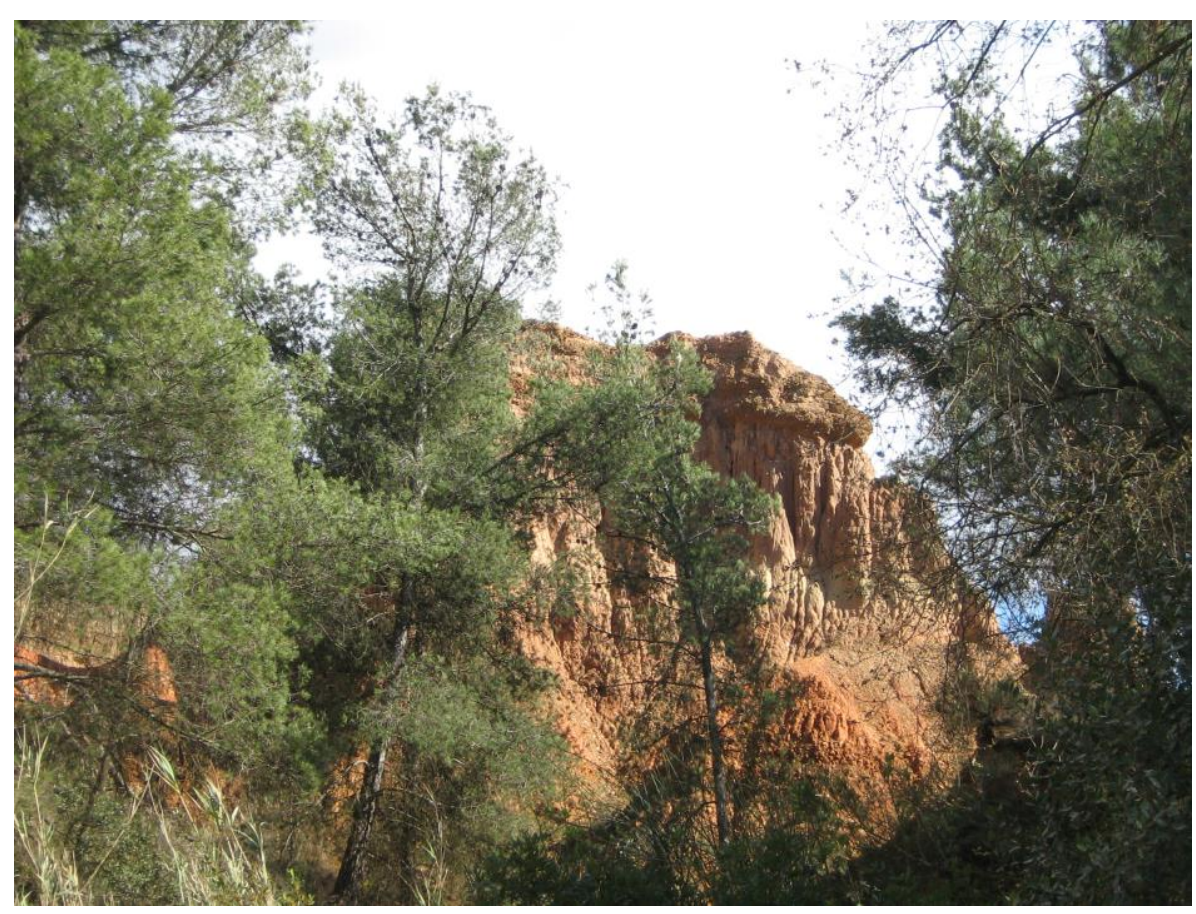

FOTOGRAFIA 1. Aspecte dels materials miocènics aixaragallats a les Flandes (Piera, el Bedorc)

PARADA 5 - CONDICIONAL. MINES DE PIROFIL.LITA DEL TORRENT DE CAN SAGRISTÀ, (Ca N'Aguilera, terme municipal de Piera, comarca d'Anoia). (Full 391).

Des de la parada anterior, cal anar de nou cap a Piera. Des d'aqui ens cal seguir cap a Vallbona d'Igualada, fins arribar al trencall que condueix cap a Ca n'Aguilera, que cal agafar. A quasi 200 metres d'agafar-lo, per l'esquerra es trobarà un camí que condueix cap a les antigues explotacions del Torrent de Can Sagristà. Aquí farem una nova aturada, a uns 4 Km de l'anterior aturadat.

En aquest recorregut. Hem anat circulant inicialment per la Depressió Prelitoral Catalana. Posteriorment, ho hem fet per la Serralada Prelitoral Catalana, on ens trobem ara situats. Així, en aquest trajecte, hem superat la Falla Nord del Vallès - Penedès, que posa en contacte les dues unitats acabades d'esmentar. El que passa es que aquesta falla es difícilment visible, per trobar-se fossilitzada pels terrenys quaternaris.

En aquest lloc hi havia una antiga explotació minera. S'aprofitaven uns nivells 
pissarrencs de l'Ordovicià, molt rics en PIROFIL.LITA. Cal dir que l'explotació va intentar explotar un talc que no s'hi trobava. Cal considerar que el talc i la pirofil.lita són dos minerals del mateix grup, i que l'explotació podia ser un error d'interpretació.

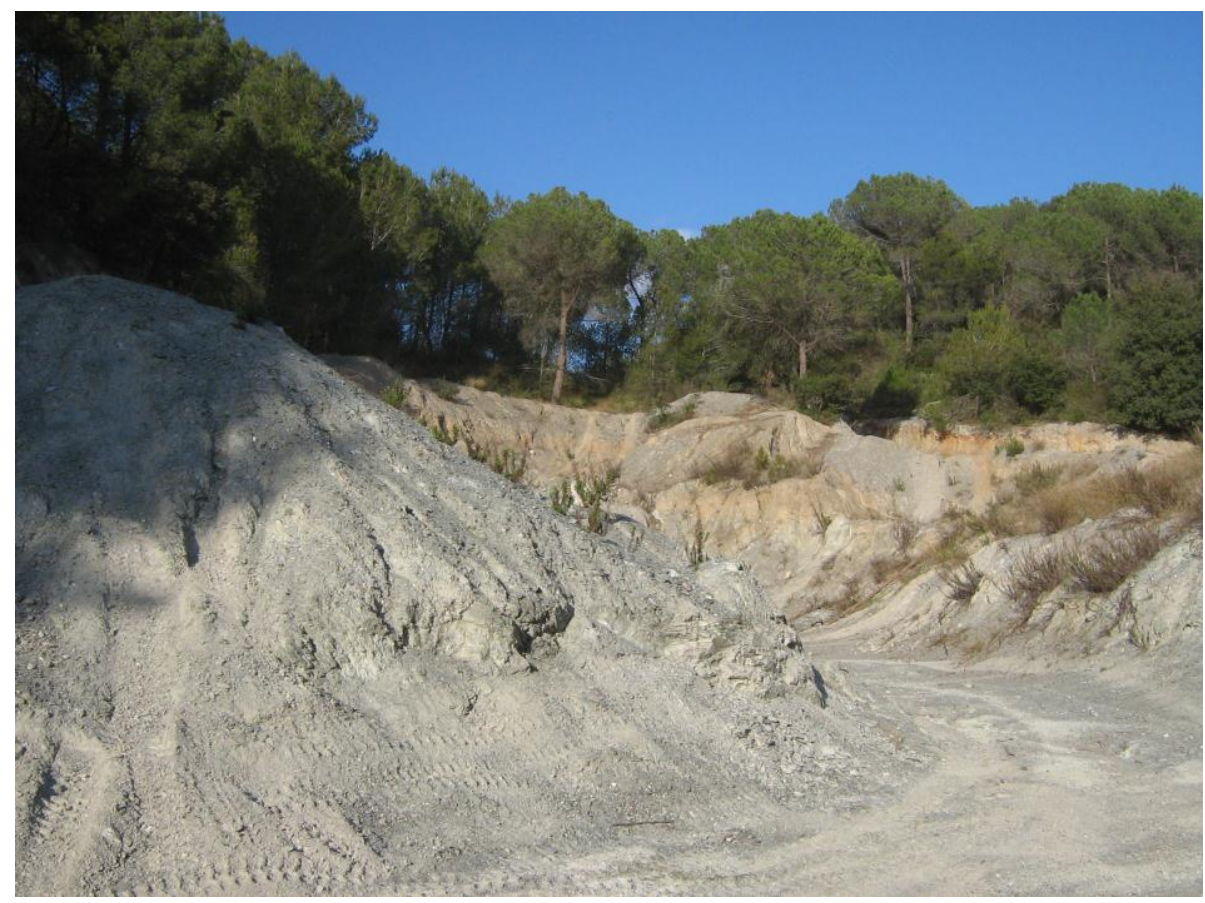

FIGURA 2. PARADA 4. Explotació de PIROFIL·LITA

\section{PARADA 6. PEDRERES DE SAULÓ, (terme municipal de Vallbona d'Anoia, o d'Igualada, comarca d'Anoia). (Full 391).}

Des de la parada anterior car agafar a la carretera B-224, per tal de continuar cap a llevant, anant cap a Vallbona d'Anoia (o d'Igualada), que s'haurà de sobrepassar. Poc després, ens caldrà parar a les explotacions de sauló, situades a uns $500 \mathrm{~m}$ del poble, a la dreta de la carretera. Així, des de la parada anterior, s'haurà fet un recorregut proper als 5 ' $5 \mathrm{Km}$.

En qualsevol cas, tot el recorregut des de la parada anterior s'efectua entre els afloraments paleozoics de llicorelles de la Serralada Prelitoral Catalana. Tot i així, ben a prop de Vallbona, s'han començat a trobar els afloraments de granodiorites i de granits, sobre els quals ara ens trobem.

En aquest indret, on es fa la present parada, es troben uns dels afloraments esmentats de granodiorites (més grisenques), i de granits (més rosats). Entre ells es troben freqüents dics de porfirs. Cal dir que tant uns com altres es troben meteoritzats i transformats en sauló. Aquests materials, d’aspecte sorrenc, són explotats com a material de construcció.

Per d'altra banda, cal dir que els materials granítics es troben en contacte amb unes llicorelles paleozoiques, a les quals els hi confereixen un cert grau de metamorfisme de contacte. 
També cal dir que s'observa la presència de petits filonets de QUARS, alguns dels quals contenen mineralitzacions de coure, amb presència de CALCOPIRITA; la qual, per alteració, ha donat lloc a la formació d'ATZURITA, i sobretot a l'abundant presència de MALAQUITA. Igualment, cal esmentar l'existència d'abundants dendrites de PIROLUSITA.

Finalment, cal dir que tot el conjunt dels afloraments anteriors, queda cobert cap al Nord, per una terrassa quaternària, corresponent al proper riu Anoia.

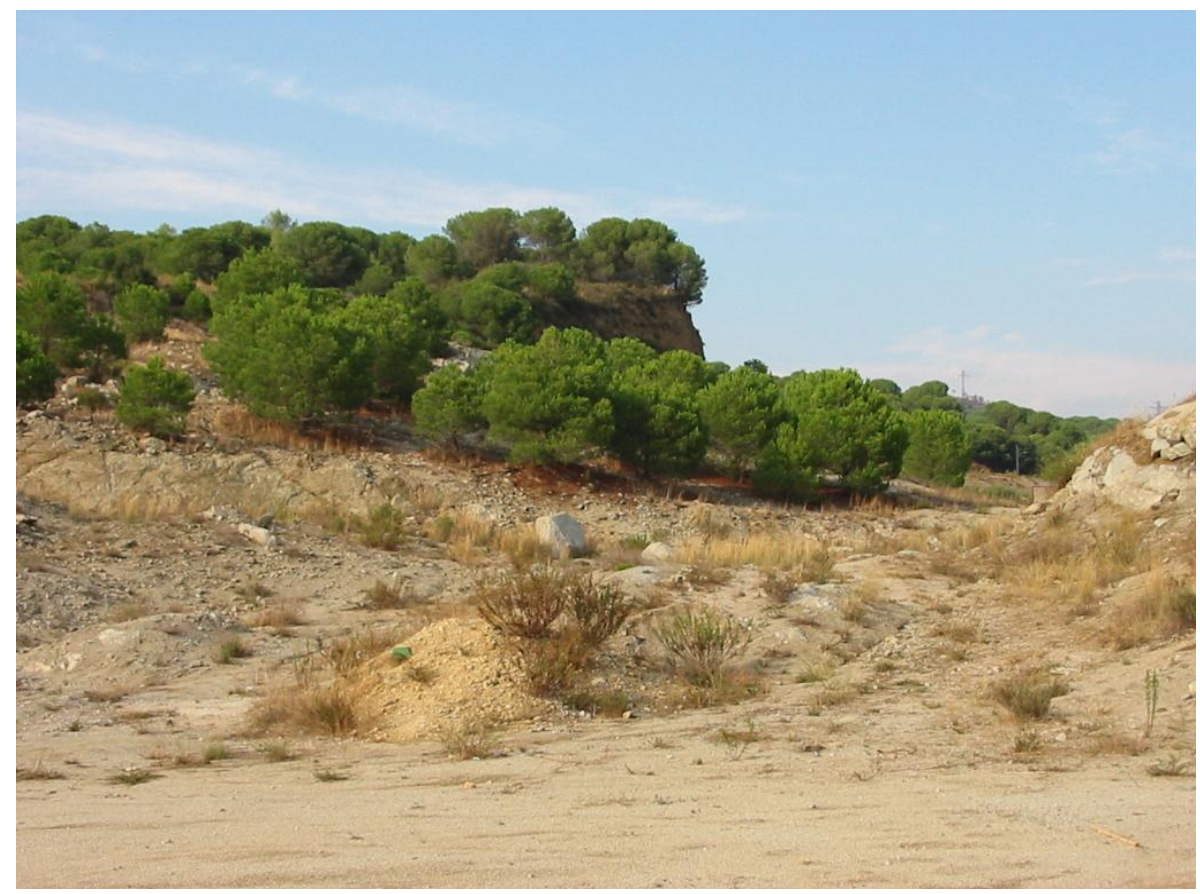

FIGURA 3. Les sauloneres de Vallbona d’Anoia

\section{PARADA 7. CONGOST DEL RIU ANOIA, (terme municipal de Capellades, comarca d'Anoia). (Full 391).}

Des de la parada anterior, cal continuar per la carretera B-224, fins arribar a la cruïlla amb la nova carretera C-244; és a dir, al "trebol" que hi ha prop de l'estació de Capellades dels FFCC. Tot seguit, cal seguir per la segona tot anant cap al Nord. En arribar al congost, que el Riu Anoía forma per sota de Capellades, cal fer la present aturada, per sota de l'anomenat Balcó de Capellades. Així, des de la parada anterior, s'haurà efectuat un recorregut proper als 2'5 Km, per tal d'arribar fins on ara som.

En tot aquest recorregut, i fins a la cruilla, s'han anat tallant els materials ja esmentats a la parada anterior. Després, de nou es tornen a trobar els nivells de licorelles paleozòiques que ja haviam trobat anteriorment. En aquest indret, es pot gaudir d'un bon lloc d'observació del Congost del riu Anoia, excavat entre els nivells de llicorelles paleozoiques (que pertanyen, com a Piera, molt probablement a l'Ordovicià). Aquestes llicorelles són d'unes tonalitats grisfosques, $\mathrm{i}$ es troben molt menys alterades que les que hem vist a la novena aturada.

Per sobre d'aquestes llicorelles, i als empeus del poble de Capellades, es troben uns afloraments de nivells carbonatats travertínics que pertanyen al Quaternari. Aquests nivells 
donen idea d'una possible i alhora important formació lacustre que devia extendre's per aquests indrets.

Aquesta formació lacustre, es trobaria originada com a consequiència d'abundants surgències d'aigües carregades de bicarbonat càlcic, procedents possiblement dels trams carbonatats del Muschelkalk; concretament de 1'Inferior i del Superior. Aquests trams carbonatats es troben més amunt, i també es fan força palesos a Cabrera d'Igualada, com veurem a la propera aturada.

Per d'altra banda, cal fer esment de l'existència de cavitats càrstiques entre els travertins, com les que han donat lloc a la formació de l'Abric Romaní, amb abundants restes arqueològics.

\section{EN AQUEST INDRET FINALITZA EL RECORREGUT DE L'ITINERARI}

\section{REFERÈNCIES BIBLIOGRÀFIQUES}

GUIMERÀ, J. ET ALTRI (1992).- GEOLOGIA (II), HISTÒRIA NATURAL DELS PAÏSOS CATALANS, VOL.2, 547 PAG. ENCICLOPÈDIA CATALANA, S.A. BARCELONA

IGME (1976A).- EXPLICACIÓN DEL MAPA GEOLÓGICO DE ESPAÑA, A ESCALA 1:50.000 (2 ${ }^{\mathrm{a}}$ SERIE). HOJA $\mathrm{N}^{\circ} 420$ (HOSPITALET DE LLOBREGAT). INSTITUTO TECNOLÓGICO Y GEOMINERO DE ESPAÑA. MINISTERIO DE INDÚSTRIA. MADRID

IGME (1976B).- EXPLICACIÓN DEL MAPA GEOLÓGICO DE ESPAÑA, A ESCALA 1:50.000 (2 $2^{\mathrm{a}}$ SERIE). HOJA N 448 (GAVÀ). INSTITUTO TECNOLÓGICO Y GEOMINERO DE ESPAÑA. MINISTERIO DE INDÚSTRIA. MADRID

MATA-PERELLÓ, J.M. (1988).- INVENTARI MINERALÒGIC DEL VALLÈS OCCIDENTAL, REVISTA XARAGALL, № 22, 26 PÀGINES. MANRESA

MATA-PERELLÓ, J.M. (1991).- ELS MINERALS DE CATALUNYA. ARXIUS DE LA SECCIÓ DE CIÈNCIES, T. XCIII, 442 PAG. INSTITUT D'ESTUDIS CATALANS. BARCELONA

MATA-PERELLÓ, J.M. (1996A).- ITINERARI GEOLÒGICO - MINERALÒGIC PER LA COMARCA D'ANOIA (AMB UNA PETITA INCURSIÓ PER L'ALT PENEDÈS): DES DE PIERA, A CAPELLADES I A CASTELLOLÍ. Inèdit, 15 pag. Manresa

MATA-PERELLÓ, J.M. (1996B).- RECERCA GEOLÒGICA I MINERALÒGICA PER LA COMARCA D'ANOÍA: DES DEL BRUC A PIERA, A VALLBONA D'ANOÍA I A CABRERA D’ANOÍA. Inèdit, 16 pag. Manresa 
MATA-PERELLÓ, J.M. (1997).- RECERCA GEOLÒGICA I MINERALÒGICA PER LA COMARCA D'ANOÍA: DES DE PIERA AL BEDORC, I DES DE VALLBONA D’ANOÍA A JORBA, PER IGUALADA. Inèdit, 16 pag. Manresa

MATA-PERELLÓ, J.M. (1998).- RECERCA GEOLÒGICA I MINERALÒGICA PER LES COMARQUES DEL BAIX LLOBREGAT I D'ANOÍA: DES DE MARTORELL A MASQUEFA I A PIERA. Inèdit, 12 pag. Manresa

MATA-PERELLÓ, J.M. (1999).- RECORREGUT DE RECERCA GEOLÒGICA I MINERALÒGICA PER LA COMARCA D'ANOÍA: DES DEL PIERA A MIRALLES. Inèdit, 16 pag. Manresa

MATA-PERELLÓ, J.M. (2006A).- RECORREGUT DE RECERCA GEOLÒGICA, GEOAMBIENTAL I MINERALÒGICA PER LES COMARQUES DEL BAIX LLOBREGAT I D'ANOIA: DES D'ESPARREGUERA A PIERA I A LA POBLA DE CLARAMUNT. Inèdit, 14 pag. Manresa

MATA-PERELLÓ, J.M. (2006B).- RECORREGUT DE RECERCA GEOLÒGICA, GEOAMBIENTAL I MINERALÒGICA PER LES COMARQUES DEL BAIX LLOBREGAT I DEL VALLÈS OCCIDENTAL: DES DEL PAPIOL A MARTORELL I A VALLBONA D’ANOIA. Inèdit, 16 pag. Manresa

MATA-PERELLÓ, J.M. (2008).- RECORREGUT DE RECERCA GEOLÒGICA, GEOAMBIENTAL I MINERALÒGICA PER LES COMARQUES DEL BAIX LLOBREGAT I D’ANOIA: DES DEL MARTORELL A VALLBONA D’ANOIA. Inèdit, 9 pag. Manresa

MATA-PERELLÓ, J.M; MATA LLEONART, R. I ESPUNY SOLANÍ, J. (2000).RECORREGUT DE RECERCA GEOLÒGICA I DE CONEIXEMENT DELS GEORRECURSOS PER LA COMARCA D'ANOÍA: DES DEL BEDORC A PIERA, I DES DE VALLBONA D’ANOIA A ORPÍ I A LA LLACUNA. Inèdit, 15 pag. Manresa

RIBA, O. ET ALTRI (1976).- GEOGRAFIA FÍSICA DELS PAÏSOS CATALANS, EDIT. KETRES, 254 PÀGINES. BARCELONA

SOLÉ SABARÍS, L. (1964).- GEOLOGIA DE LOS ALREDEDORES DE BARCELONA. COLECCIÓN LA "NUEVA GEOGRAFIA", MINIST. DE EDUC. NACIONAL. 135 PAG. BARCELONA 